\title{
Creativity in an Affective Context
}

\section{Reappraisal Inventiveness and Malevolent Creativity as Extensions of Creativity Research Toward More Real-World Creative Behavior}

\author{
Corinna M. Perchtold-Stefan@, Ilona Papousek, Christian Rominger, and Andreas Fink \\ Department of Psychology, University of Graz, Austria
}

\begin{abstract}
Everyday life often requires considerable creativity in dealing with challenging circumstances. This implies that creativity regularly operates in an affective context, however, this "C" of creativity is rarely addressed in contemporary research. In this brief review article, we address some important milestones in this nascent field of research. Starting with early accounts on emotional creativity, we discuss seminal research intertwining creativity and mood states, and finally introduce two recent developments in this field: reappraisal inventiveness as the capacity to generate manifold cognitive reappraisals for aversive situations, and malevolent creativity as creative ideation intentionally used to damage others. We discuss the conceptual origins of reappraisal inventiveness and malevolent creativity and provide an extensive review of past behavioral and neuroscientific findings regarding these differently motivated instances of affective creativity. Additionally, novel pilot findings and prospects on both lines of research will be provided, which may help to advance investigations into more real-world applications of creative cognition.
\end{abstract}

Keywords: affective creativity, cognitive reappraisal, malevolent creativity, 7 C's, context

In the past, creativity research has faced the criticism that it is rarely concerned with spontaneous, real-life creative ideation, due to its predominant focus on verbal divergent thinking (e.g., generating alternative objects uses in the Alternative Uses Task [AUT]; see Tanggaard, 2013). However, new and exciting avenues for investigating more complex, real-life types of creative behavior have emerged since then, with more and more studies investigating creative processes in sports like soccer (Fink, Rominger, et al. 2018; Fink et al. 2019; Rominger, Memmert, et al., 2020), artistic talent and drawing (Chen et al., 2020; Rominger et al., 2018), musical improvisation (Beaty, 2015, Rosen et al., 2020), and even humor (Perchtold-Stefan, Papousek, et al., 2020). Another type of creativity ubiquitous in daily life, which has only recently attracted scientific attention, is creativity in an affective context. In the 7 C's model of creativity (Lubart, 2017), emotions are noted as a crucial part of the creative process and maybe products or antecedents of creating. However, the $7 \mathrm{C}$ model also states that certain physical but also social contexts may impact creative ideation - and there are plenty of emotional contexts in daily life that may facilitate or modulate creative ideation. In this article, we will undertake an exciting journey from early accounts on emotional creativity, over seminal research intertwining creative thinking and mood states, to more novel positive and negative applications of creativity reflected in the cognitive reappraisal of aversive events and in malevolent creativity utilized to inflict damage upon others.

\section{The Concept of Emotional Creativity}

In the early 1990s, Averill and colleagues were among the first to propose that creativity and emotion were not separate entities, but rather, that creative thinking may be applied to the daily management of emotions. More precisely, emotions were considered as products of creative activity, which necessitates the definition of specific criteria that must be met for an emotional response to be deemed creative. Accordingly, the concept of emotional creativity was coined as the experience and expression of original, effective, and authentic assortments of emotions (Averill, 1999; Averill \& Nunley, 1992), with these criteria, precisely matching those of cognitive creativity (see, e.g., Runco \& Jaeger, 2012). Whereas a novel/original emotional response may be understood as deviating from one's typical behavior or conventional response patterns in everyday life, the aspect of appropriateness/effectivity designates emotional 
responses that are beneficial to oneself and/or others in specific contexts (see Fuchs et al., 2007). Similar to classic, cognitive creativity, emotional creativity also involves a vast amount of intra- and interpersonal differences. Findings with the personality-based Emotional Creativity Inventory (ECI; Averill, 1999) show that individuals perceiving themselves as more emotionally creative also invent more emotional endings to hypothetical conflict stories and draw more complex pictures of emotions (Averill, 1999). Women also report higher emotional creativity than men, and selfreported emotional creativity was linked to higher positive affect and state hopefulness (for a recent meta-analysis, see Kuška et al., 2020). Moreover, scores on the ECI are also positively correlated with openness to experience (Averill, 1999; Ivcevic et al., 2007) as well as fantasy proneness, and self-perceived creative capacity (Fuchs et al., 2007). While not directly treating emotions as creative products, related approaches also investigated creative thinking as a precursor of mood, following the idea that thought processes may induce particular mood states. Among affective constructs, emotions reflect momentary, object-specific, and intense affective reactions, whereas moods refer to longer-lasting, mild affective states that are often critically intertwined with cognition and behavior (for a summary, see Madrid \& Patterson, 2018). Chermahini and Hommel (2012) showed that divergent thinking led to improvements in individuals' mood after task performance, whereas convergent thinking had the opposite effect. As another interesting prospect, Hirt et al. (2008) suggested that happy individuals use purposefully creative thinking to sustain their positive mood states, hinting at affect-regulatory functions of creativity. Notably, while this at a minimum suggests a reciprocal relationship between creative thinking and affective processes, to date, most of the research examines emotions and mood states as predictors and mediators of creative cognition.

\section{Effects of Mood and Emotion on Creativity}

Conceptually different from Averill's (1999) personality approach to emotional creativity, the large body of research scrutinizing creativity as a function of mood advocates the idea that creative performance is subject to contextual affective factors (for an overview, see Baas, 2019, also see Isen, 1984, Isen et al., 1987). Here, different approaches include experimental manipulations of individuals' mood states (e.g., by having them recall autobiographical memories or watching emotional movie clips), with subsequent creativity assessment in standardized tasks (e.g., Baas et al., 2011; De Dreu et al., 2008), or correlating self-reported mood states in questionnaires with creative performance or self-reported creativity (Silvia et al., 2014). Further, ambitious investigations link fluctuations in mood and creativity over several days or weeks (e.g., Conner et al., 2018; Conner \& Silvia, 2015; Karwowski et al., 2017). Additionally, it has been posited that creativity may be influenced by the dynamic interplay of positive and negative affect. Underlining their notion of "affective shift," Bledow et al. (2013) demonstrated significant increases in creativity when individuals shifted from episodes of negative affect to episodes of positive effect, both within several minutes and over the course of a day. One of the most influential models in mood-creativity research is the Dual Pathway to Creativity Model (DPCM; Baas et al., 2008; De Dreu et al., 2008, 2011). According to the DPCM, both positive and negative moods may advance creative performance; however, they need to have an activating hedonic tone (e.g., feeling happy as positive activation; feeling angry or afraid as negative activation; De Dreu et al., 2012). Moreover, the DPCM proposes different routes to creativity through positive and negative activating moods. Positive activation is believed to increase creativity through heightened cognitive flexibility because individuals feel safe to explore novel features in their environment. Conversely, negative activation is believed to increase creativity through cognitive persistence, because individuals are more analytical and focus on in-depth explorations of ideas (Baas et al., 2008; De Dreu et al., 2008; Nijstad et al., 2010). To date, there is considerable empirical support for these two mood pathways to creative performance (see Baas, 2019), which have even been extended from the individual level to team and organizational creativity (e.g., Emich \& Vincent, 2020)

\section{Creativity in an Affective Context}

All these exciting research traditions have also inspired other research approaches that examine creativity in relation to positive and negative emotional contexts. In recent years, there is an increasing interest in creative processes that are specifically used for resolving negative situations, which calls attention to creative behavior in emotion regulation and social problem-solving. This leads to two interesting instances of creativity employed in similar affective contexts: (1) the inventiveness in generating positive reappraisals for stressful events and (2) malevolent creativity utilized to inflict damage upon others, which are subsequently outlined in terms of their conceptual origins, cognitive, behavioral, and neuronal correlates, and future perspectives. This concept of "creativity in an affective context" is rooted in the maximum-performance approach to creativity, where the creative potential of individuals is 
usually measured by their capacity to generate many original solutions to neutral, open-ended problems in the laboratory (see e.g., Fink \& Benedek, 2014). However, observations of creative thinking in more ecologically valid situations in everyday life show clearly that individuals also display remarkable inventiveness and originality when it comes to successful problem-solving in negative affective contexts.

\section{Reappraisal Inventiveness: Creativity in Generating Alternative Reappraisals for Stressful Events}

In general terms, cognitive reappraisal denotes the deliberate re-interpretation of an emotionally evocative event in order to change its emotional impact (Gross \& John, 2003; Lazarus \& Folkman, 1984). Positive reappraisal is considered particularly adaptive for dealing with stressful events (see Webb et al., 2012), and specific cognitive processes are considered vital for the flexible adoption of new perspectives in the face of adversity. Among the assumed core components of successful positive reappraisal are basic executive functions such as the inhibition of dominant emotional representations, updating of working memory content, as well as flexible cognitive switching and shifting between divergent ideas and thought patterns (e.g., Joormann \& Gotlib, 2010; Malooly et al., 2013; Zaehringer et al., 2018). These executive control processes have been established as crucial prerequisites for creativity as well (see Beaty \& Silvia, 2012; Fink \& Benedek, 2014; Gonen-Yaacovi et al., 2013). Moreover, their intricate interaction with default network processes (loose associations, mind-wandering) has been proposed as a neural marker of truly original ideas (Beaty et al., 2015, 2016). While there may indeed be something creative to contriving one alternative perspective for an emotional scenario, parallels between positive reappraisal and creative ideation are most obvious when reappraisal is investigated as an actual capacity, and not as a self-reported tendency to use positive reappraisal in daily life (e.g., Gross \& John, 2003). Conceptually different from what individuals report they habitually do, Weber et al. (2014) coined the concept of reappraisal inventiveness, which denotes the ability to invent spontaneously manifold different positive reappraisals for stressful events. In the corresponding Reappraisal Inventiveness Test (RIT; Weber et al., 2014), individuals are confronted with selfrelevant anger- or anxiety-eliciting situations (e.g., a friend not keeping their promise to water one's plants during a vacation; having to walk through a dark park alone at night, etc.), and are instructed to generate as many different ideas as possible with the goal of reducing the elicited emotion (see Electronic Supplementary Material, ESM 1 for a schematic depiction of the RIT). This process of divergent thinking in terms of finding multiple and alternative, preferably original yet practical solutions to an open-ended problem fits the common notion of creative thinking (Runco \& Jaeger, 2012; also see Fink, Perchtold, et al., 2018; Perchtold, Papousek, et al., 2018). This presumed overlap in cognitive processes was empirically substantiated: Weber et al. (2014) reported that RIT performance in terms of fluent and flexible idea generation was significantly associated with verbal divergent thinking ability, with subsequent studies replicating these strong correlations ( $r$ 's of up to .66; e.g., Fink et al., 2017; Perchtold, Papousek, et al., 2018; Rominger et al., 2018). In terms of creativity-related traits, flexible idea production in the RIT was also linked to the personality dimension of openness (Weber et al., 2014), corroborating the creativity-related demands in reappraisal inventiveness. In addition to the behavioral validation of the RIT, however, research has also revealed relevant evidence from neuroscience studies that further reinforce the idea of cognitive reappraisal generation as creativity operating in an affective context.

\section{Neural Activation Patterns in Reappraisal Inventiveness and Creative Ideation Without Emotional Components}

The link between creativity and EEG alpha activity constitutes one of the most robust findings in the neuroscience of creative cognition (e.g., Fink \& Benedek, 2014; Kounios \& Beeman, 2014; Stevens \& Zabelina, 2019). This line of research is nicely supplemented with studies on transcranial alternating current stimulation (tACS) providing evidence that alpha oscillations serve as a causal mechanism for creative thoughts (Grabner et al., 2018; Luft et al., 2018). Fink et al. (2017) compared task-related changes in EEG alpha power during reappraisal generation in the RIT and creative ideation in the classic Alternative Uses Task (AUT). The authors demonstrated that functional patterns of brain activity during both tasks were remarkably similar, both yielding comparatively strong alpha power increases at prefrontal sites. This was interpreted in terms of top-down control and the active inhibition of task-irrelevant sensory processing, complementing findings of other EEG studies (Fink \& Benedek, 2014; Jaarsveld et al., 2015; Rominger et al., 2019; also see Agnoli et al., 2020). This finding also matched functional neuroimaging studies denoting prefrontal engagement as a hallmark of creative cognition (Beaty et al., 2016; Boccia et al., 2015; GonenYaacovi et al., 2013). However, Fink et al. (2017) also found unique brain activity patterns during the RIT, indicating 
that reappraisal generation (compared to classic creativity) required stronger executive control necessary to modify affective information and at the same time, less dependence on spontaneous imaginative modes (Fink, Perchtold, et al., 2018; Fink et al., 2017; also see Papousek, Weiss, et al., 2017). In a subsequent study, Perchtold, Papousek, et al. (2018) elaborated on similarities and differences in brain activation between reappraisal inventiveness and classic creative ideation using fMRI. Using rigorously matched tasks that included immersive audio stories for the RIT and the AUT, this study showed that both creativity tasks elicited activation in a left frontal cognitive control network. This finding confirmed the relevance of executive functions, necessary for the inhibition of prepotent responses and the flexible adoption of new thought patterns that exceed routines, in both the generation of alternative uses and creative reappraisals (see Fink, Perchtold, et al., 2018; Fink et al., 2017). These shared demands on executive control were further supported by Rominger et al. (2018), who found both performances in the RIT and a verbal divergent thinking test being positively linked to greater basic inhibition skills. Yet, Perchtold, Papousek, et al. (2018) also uncovered a specific network that was only specifically activated by reappraisal. This network involved, among others, right frontal regions, possibly indicating an override of dominant affective responses as well as monitoring of reappraisal success, and regions strongly implicated in social cognition and mental imagery (Perchtold, Papousek, et al., 2018). It may thus be concluded that if creative thinking is applied to a positive reappraisal of stressful events, it requires additional cognitive control over emotional content (see Rominger et al., 2018), as well as stronger mental explorations of social perspectives (Fink, Perchtold, et al., 2018; Fink et al., 2017; Perchtold, Papousek, et al., 2018).

\section{Creative Ways to Well-Being: Correlates of Reappraisal Inventiveness}

Reappraisal inventiveness has also been linked to practical measures of well-being and psychological functioning in daily life, providing a crucial step toward exploring correlates of creative ideation in more natural contexts. Studies showed that female students with a higher capacity for the generation of manifold reappraisals in critical situations reported lower chronic stress perception in daily life, a link that was underpinned by more appropriate recruitment of the prefrontal cortex during reappraisal generation (Perchtold, Fink, et al., 2018; also see Papousek, Weiss, et al., 2017). Higher reappraisal inventiveness in the face of adversity also predicted lower proneness for hostile and suspicious thoughts (Perchtold, Papousek, et al., 2019), and fewer depressive experiences in men within a student sample (Perchtold, Weiss, et al., 2019). These findings corroborate the notion that individuals' capacity for generating a broad pool of divergent reappraisal ideas may facilitate successful reappraisal implementation in daily life, particularly in novel situations that exceed routines (also see Weber et al., 2014). Despite being cross-correlational in nature, these studies propose that high inventiveness in spontaneously generating reappraisals for critical situations may provide individuals with creative ways to well-being in daily life. This prompts the question of whether individuals' reappraisal inventiveness can be enhanced with targeted interventions.

\section{An Intervention Approach to Reappraisal Inventiveness: Pilot Findings and Future Perspectives}

With creativity denoted as an axiomatic skill for navigating the complexities of modern society (Runco, 2004), research is adamantly interested in how creative ideation can be trained. Here, several studies demonstrate an effect of cognitive interventions like creative ideation training or divergent thinking exercises that have participants practice creativity while providing specific rules and techniques (e.g., Benedek et al., 2006; Fink et al., 2015; Ritter \& Mostert, 2017; Scott et al., 2004). As an intriguing example in the field, Fink et al. (2020) showed recently that divergent thinking training over only two school lessons significantly increased verbal and figural creativity in primary-school children. Using even shorter intervention intervals and probing effects on the level of the brain, Fink et al. (2011) had previously demonstrated significant EEG alpha power increases in the prefrontal cortex during creative ideation, both after participants were exposed to ideas of others (cognitive stimulation) or the heartfelt laughter of others (affective stimulation). Similar brain activation increases as a function of creativity training or exposure to the ideas of others were also reported in fMRI studies (Fink et al., 2012, 2015). Adopting the idea of a short-term creativity intervention for reappraisal inventiveness, we conducted recently an EEG study that had participants work on the RIT before and after a $15 \mathrm{~min}$ reappraisal training that informed on a variety of reappraisal strategies classified as presumedly more effective positive re-interpretations (see Perchtold et al., 2020b; Perchtold, Fink, et al., 2018). Preliminary analyses revealed significant behavioral effects denoting an increase in both ideational fluency and the number of generated positive re-interpretations posttraining. Additionally, a post-training increase in prefrontal EEG alpha power was observed (see Fink et al., 2011); however, this effect only emerged for participants with 
enhanced RIT performance post-training, who benefited more from the intervention. Though preliminary, these observed behavioral and neuronal changes may suggest the trainability of affective creativity using a single training unit for positive reappraisal, which may also have the potential to enhance well-being in daily life (see Perchtold, Fink, et al., 2018; Perchtold, Papousek, et al., 2019; Perchtold, Weiss, et al., 2019). Following another intriguing research line that demonstrated positive effects of physical activity (interventions) on creative ideation (e.g., walking: Oppezzo \& Schwartz, 2014; cycling: Colzato et al., 2013; for a recent study considering the influence of positive affect, see Rominger, Fink, et al., 2020), it will also be interesting to see whether mild (e.g., slackline training) or more daring physical activity interventions (e.g., learning unicycling, running) may improve certain aspects of reappraisal inventiveness, and how respective changes are mirrored in the brain (e.g., Weber et al., 2019).

\section{Malevolent Creativity: Creativity in Generating Ideas for the Purpose of Damaging Others}

Another example of creativity operating in an affective context is malevolent creativity. Parting with the positive assumption that creative ideas and products are inherently beneficial to individuals and society (e.g., Stein, 1953; Sternberg, 2010), malevolent creativity refers to creative thinking that is purposefully used to inflict mental, physical, or material harm on others (Cropley, 2010; Cropley et al., 2008). A defining feature of malevolent creativity is the intentional pursuit of malicious goals (e.g., deliberately sabotaging a coworker to cost them a promotion), as opposed to the unintended collateral damage of creative ideas, which is termed negative creativity (e.g., creatively avoiding office work at the expense of other coworkers; see James et al., 1999). Although malevolent creativity may be highly destructive on a larger scale, for example, in instances of creative terrorism or unique warfare, in daily life, it is also frequently exercised more covertly, take lying, bullying, harassment, deception, and even aggressive humor (e.g., Cropley, 2010; Harris et al., 2013). Importantly, while malevolent creativity may be exercised without motive, it is assumed that in the general population, it is more likely to occur in unfair and provocative social situations (e.g., Harris \& Reiter-Palmon, 2015; also see Baas et al., 2019). Accordingly, malevolent creativity may be prompted by similar affective contexts as positive reappraisal, particularly where anger-eliciting situations are concerned. Several studies used this approach to elicit malevolent creativity in experimental settings, by having participants generate malevolently creative ideas to a negative social scenario (to take revenge on someone, e.g., Hao et al., 2016, 2020; Harris \& Reiter-Palmon, 2015), whereas others scrutinized individuals' self-reports of their malevolent creativity behavior in daily life (Hao et al., 2016; Khorakian et al., 2020).

\section{Measuring Malevolent Creativity With a Psychometric Test}

While to date, there is no widely used "standard test" for malevolent creativity (e.g., compared to the AUT for classic creativity or the RIT for affective creativity in terms of reappraisal inventiveness), Perchtold-Stefan et al. (2020b) proposed the Malevolent Creativity Test (MCT) as a timesensitive, multi-item approach to measuring individuals' theoretical capacity for malevolent creativity, in order to provide a better approximation to common psychometric creativity tests. In the four items of the MCT, individuals are confronted with anger-eliciting social situations and are instructed to generate as many original and malevolent ideas as possible in order to take revenge on or sabotage a wrongdoer (cf. Harris \& Reiter-Palmon, 2015), with a time limit of 3 min per item (cf. Fink et al. 2017). Total malevolent creativity is then computed by scoring several ideas that are both, at least minimally malevolent (e.g., denying the wrongdoer any help in the future) and moderately original (scored by several independent raters, see Harris et al., 2013; Harris \& Reiter-Palmon, 2015). See ESM 2 for a schematic depiction of the MCT. Measuring malevolent creativity with a performance test allowed to examine correlations with individuals' capacity for classic creative cognition, which was previously only assumed or tested using selfreport (e.g., self-reported creative potential and selfreported malevolent creativity behavior; Hao et al., 2016, 2020). Perchtold-Stefan et al. (2020b) found that students $(n=105)$ higher in malevolent creativity on the MCT were also more fluent in conventional verbal creative ideation $(r=.36)$, suggesting shared cognitive factors that facilitate divergent thinking across different contexts. Of note, the ecological validity of the MCT was further underlined by positive correlations of MCT performance with selfreported malevolent creativity behavior in everyday life (lying, playing tricks, hurting people; Hao et al., 2016). This lends support to the notion that individuals' potential for malevolent creativity may, in part, translate to actual malicious behavior in the face of social provocation (PerchtoldStefan et al., 2020b). Yet, it has been questioned whether the self-report scale by Hao et al. (2016) well captures malevolent creativity and not more generally, negative 
behavior, since most questionnaire items do not specifically refer to aspects of novelty or originality of malevolent acts (see Reiter-Palmon, 2018). This may indicate a need for the development of more creativity-focused self-report scales of malicious behavior. Importantly, however, there are also individual differences to be considered in the occurrence of malevolent ideation highlighting the question of who is malevolently creative.

\section{Linking Malevolent Creativity to Personality Traits, Social Goals, and Emotion Regulation}

Although certain situational variables facilitate malevolent problem-solving (e.g., Baas et al., 2019; Perchtold-Stefan et al., 2020b, also see Barbot et al., 2020), there is ample evidence that various aggressive traits may lead to increased malevolent creativity as well. In this regard, studies suggest implicit and physical aggression, antagonism, lower conscientiousness as well as psychopathic traits, and Machiavellianism as personality factors contributing to malevolent creativity (e.g., Hao et al., 2016, 2020; Harris \& Reiter-Palmon, 2015, Jonason et al., 2017). Antagonism (but not negative affectivity, detachment, disinhibition, or psychoticism as measured by the Personality Inventory for DSM-5) also emerged as a unique predictor of malevolent creativity in the MCT (Perchtold-Stefan et al., 2020b). A higher capacity for malevolent creative ideation was further reported for individuals with a higher preference for using dark, malicious humor (e.g., sarcasm, irony, cynicism; Perchtold-Stefan et al., 2020a). For an interpretation, the authors suggested shared motivations in the generation of malicious ideas and the use of dark humor, which may be attributed to latent interpersonal goals aimed at hurting, upsetting, or dominating others (Papousek, Ruch, et al., 2017). Malevolent creativity has also been investigated in terms of affective correlates like individuals' current mood states, with reports that less positive affect, greater state anger, or manipulations of social threat increased malevolent creativity in subsequent behavioral tests (Baas et al., 2019; Khorakian et al., 2020; Perchtold-Stefan et al., 2020b). Harris et al. (2013) addressed more specifically emotional abilities and demonstrated a negative relationship between malevolent creativity and emotional intelligence, even in situations without social/emotional components, concluding that individuals high in malevolent creativity were more willing to disclose and thus, potentially act on their destructive ideas. Becasue both reappraisal inventiveness and malevolent creativity may be instigated by anger-eliciting social situations, Perchtold-Stefan et al. considered how they may be related to each other, contrasting their overlap in cognitive features with their fundamentally different goals (RIT: positively re-interpreting upsetting scenarios vs. MCT: creatively inflicting harm on wrongdoers). Ideational fluency scores in the RIT and the MCT were positively correlated, underpinning a general proneness for divergent thinking irrespective of task or problem (Perchtold-Stefan et al., 2020b). However, crucial differences emerged in qualitative aspects of idea generation. Higher malevolent creativity was associated with a higher proneness for revenge-related ideation during reappraisal attempts and reduced the number of neutral, problem-oriented reappraisals. This preliminary pattern suggests that malevolent creativity may impede successful coping with anger-eliciting events, and as a result, may stimulate antagonistic problem-solving in daily life (Perchtold-Stefan et al., 2021). Altogether, the abovementioned studies corroborate that different cognitive and affective factors, along with personality traits and emotional capabilities, need to be considered when parsing the destructive phenomenon of malevolent creativity.

\section{Future Research Directions With Malevolent Creativity}

Building on behavioral correlates of malevolent creative ideation, it will be an important avenue for the future to examine how this instance of affective creativity is rooted in the brain. In principle, it may be assumed that the neural signature of malevolent creativity corresponds to activation patterns observed during classic creativity (e.g., AUT), due to shared divergent thinking processes, and may for example entail similar EEG alpha power increases at frontal and posterior cortical sites (see Fink \& Benedek, 2014, for a review). Yet, there may also be distinct neuronal correlates for creative ideation intentionally used to harm others, like a stronger interplay of cognitive and affective processes, as have been identified for reappraisal inventiveness (Fink et al., 2017; Fink, Perchtold, et al., 2018; Perchtold, Papousek, et al., 2018). While several studies are tracing neuronal correlates of aggressive and retaliatory behavior (for a review, see Fanning et al., 2017), they have not been concerned with the aspect of creativity in vengeful ideation to date. Next to contrasting malevolent and classic creative ideation using EEG and fMRI, machine learning approaches in terms of pattern recognition models may be particularly useful to determine which combination of brain regions is involved in specific aspects of malevolent creativity (e.g., ideational fluency; harmfulness of ideas). This method has already successfully been applied to predict originality in more real-life types of creativity (e.g., creative soccer moves; Rominger, Koschutnig, et al., 2021). Additionally, it would be interesting to compare brain activation patterns of different groups engaging in malevolent creative ideation, for example, the general population versus samples of convicted criminals or individuals high in psychopathic traits 
(see behavioral investigations by Barbot et al., 2020; Jonason et al., 2017), in order to gain better insights into what makes individuals act on their potential for malicious ideation.

\section{Guidelines for Future Research on Reappraisal Inventiveness and Malevolent Creativity}

Future research on creativity in an affective context will have to master several challenges. What is needed is a refined conceptual model as to how the idea of reappraisal inventiveness and malevolent creativity as maximum-performance approaches to creative potential may overlap with but also be differentiated from Averill's emotional creativity, as well as prominent frameworks linking mood and creativity (e.g., Baas, 2019). One perspective is that contextspecific negative emotions may act as precursors of specific types of creative thinking (i.e., a creative reappraisal or an original idea for revenge), which would correspond to mood effects on creative ideation. However, there is also the perspective that creative reappraisal and malevolent ideation serve affect-regulatory functions and may produce novel emotional responses that are creative products themselves. Another crucial step of experimental research will be the manipulation of individuals' mood before having them work on social problem-solving tasks that allow for both creative reappraisals or malevolent creativity, in order to gain a better understanding of state influences (e.g., happy mood) and individual difference variables (e.g., trait aggression) that may mobilize individuals toward more positive or negative affective creativity. This may also stimulate research on the effects of fluctuating moods on creativity (e.g., Conner et al., 2018) and could be extended to the level of teams and organizations in order to enrich research on innovative work behavior (see Emich \& Vincent, 2020; Madrid \& Patterson, 2018). Further, novel powerful research tools like ecological momentary assessments of creative ideation (see Cotter \& Silvia, 2019; Rominger, Fink, et al., 2021) will provide critical insights into moment-to-moment fluctuations of reappraisal inventiveness and malevolent creativity and may allow for hitherto unprecedented lines of research.

\section{Conclusion}

The 7 C's model of creativity (Lubart, 2017) identifies the context of creative processes as a major theme of interest for future creativity research. Building on the concept of emotional creativity and research linking mood and creativity, we proposed that individuals' inventiveness in generating positive reappraisals for stressful situations and individuals' capacity for malicious creative cognition may denote two fresh and new instances of creativity operating in an affective context that may serve as an important approximation to more real-world creative behavior. Accordingly, psychometric tests like the RIT (Weber et al., 2014) or the MCT (Perchtold-Stefan et al., 2020b) may provide novel tools and methodology to investigate how individuals apply their creative potential to problemsolving in more ecologically valid situations. In addition, modern neuroscientific methods may help to identify relevant brain functions underpinning creativity as a means of social problem solving, which may ultimately help combat individual deficits in terms of dysregulated emotions as well as violent actions toward society caused by sophisticated crime and warfare.

\section{Electronic Supplementary Materials}

The electronic supplementary material is available with the online version of the article at https://doi.org/ 10.1027/1016-9040/a000448

ESM 1. Includes a list of RIT items and a schematic depiction of one RIT item.

ESM 2. Includes a list of MCT items and a schematic depiction of one MCT item.

\section{References}

Agnoli, S., Zanon, M., Mastria, S., Avenanti, A., \& Corazza, G. E. (2020). Predicting response originality through brain activity: An analysis of changes in EEG alpha power during the generation of alternative ideas. Neurolmage, 207, Article 116385. https:// doi.org/10.1016/j.neuroimage.2019.116385

Averill, J. R. (1999). Individual differences in emotional creativity: Structure and correlates. Journal of Personality, 67(2), 331371. https://doi.org/10.1111/1467-6494.00058

Averill, J. R., \& Nunley, E. P. (1992). Voyages of the heart: Living an emotionally creative life. Free Press.

Baas, M. (2019). In the mood for creativity. In J. C. Kaufman \& R. J. Sternberg (Eds.), The Cambridge handbook of creativity (pp. 257-272). Cambridge University Press.

Baas, M., De Dreu, C. K., \& Nijstad, B. A. (2008). A meta-analysis of 25 years of mood-creativity research: Hedonic tone, activation, or regulatory focus? Psychological Bulletin, 134(6), 779806. https://doi.org/10.1037/a0012815

Baas, M., De Dreu, C. K., \& Nijstad, B. A. (2011). When prevention promotes creativity: The role of mood, regulatory focus, and regulatory closure. Journal of Personality and Social Psychology, 100(5), 794-809. https://doi.org/10.1037/a0022981

Baas, M., Roskes, M., Koch, S., Cheng, Y., \& De Dreu, C. K. (2019). Why social threat motivates malevolent creativity. Personality 
and Social Psychology Bulletin, 45(11), 1590-1602. https://doi. org/10.1177/0146167219838551

Barbot, B., Cerda, K., \& Teo, T. (2020). Negative ideation in creative problem-solving is task-specific too: Evidences from a sample of incarcerated juveniles. Thinking Skills and Creativity, 38, Article 100740. https://doi.org/10.1016/j.tsc.2020. 100740

Beaty, R. E. (2015). The neuroscience of musical improvisation. Neuroscience and Biobehavioral Reviews, 51, 108-117. https:// doi.org/10.1016/j.neubiorev.2015.01.004

Beaty, R. E., Benedek, M., Kaufman, S. B., \& Silvia, P. J. (2015). Default and executive network coupling supports creative idea production. Scientific Reports, 5(1), 1-14. https://doi.org/ 10.1038/srep10964

Beaty, R. E., Benedek, M., Silvia, P. J., \& Schacter, D. L. (2016). Creative cognition and brain network dynamics. Trends in Cognitive Sciences, 20(2), 87-95. https://doi.org/10.1016/j. tics.2015.10.004

Beaty, R. E., \& Silvia, P. J. (2012). Why do ideas get more creative across time? An executive interpretation of the serial order effect in divergent thinking tasks. Psychology of Aesthetics, Creativity, and the Arts, 6(4), 309-319. https://doi.org/10.1037/ a0029171

Benedek, M., Fink, A., \& Neubauer, A. C. (2006). Enhancement of ideational fluency by means of computer-based training. Creativity Research Journal, 18(3), 317-328. https://doi.org/ 10.1207/s15326934crj1803_7

Bledow, R., Rosing, K., \& Frese, M. (2013). A dynamic perspective on affect and creativity. Academy of Management Journal, 56(2), 432-450. https://doi.org/10.5465/amj.2010.0894

Boccia, M., Piccardi, L., Palermo, L., Nori, R., \& Palmiero, M. (2015). Where do bright ideas occur in our brain? Meta-analytic evidence from neuroimaging studies of domain-specific creativity. Frontiers in Psychology, 6, Article 1195. https://doi.org/ 10.3389/fpsyg.2015.01195

Chen, Q., Beaty, R. E., \& Qiu, J. (2020). Mapping the artistic brain: Common and distinct neural activations associated with musical, drawing, and literary creativity. Human Brain Mapping, 14(12), 3403-3419. https://doi.org/10.1002/hbm.25025

Chermahini, S. A., \& Hommel, B. (2012). Creative mood swings: Divergent and convergent thinking affect mood in opposite ways. Psychological Research, 76(5), 634-640. https://doi.org/ 10.1007/s00426-011-0358-z

Colzato, L. S., Szapora Ozturk, A., Pannekoek, J. N., \& Hommel, B. (2013). The impact of physical exercise on convergent and divergent thinking. Frontiers in Human Neuroscience, 7, Article 824. https://doi.org/10.3389/fnhum.2013.00824

Conner, T. S., DeYoung, C. G., \& Silvia, P. J. (2018). Everyday creative activity as a path to flourishing. The Journal of Positive Psychology, 13(2), 181-189. https://doi.org/10.1080/17439760. 2016.1257049

Conner, T. S., \& Silvia, P. J. (2015). Creative days: A daily diary study of emotion, personality, and everyday creativity. Psychology of Aesthetics, Creativity, and the Arts, 9(4), 463-470. https://doi.org/10.1037/aca0000022

Cotter, K. N., \& Silvia, P. J. (2019). Ecological assessment in research on aesthetics, creativity, and the arts: Basic concepts, common questions, and gentle warnings. Psychology of Aesthetics, Creativity, and the Arts, 13(2), 211-217. https://doi.org/ 10.1037/aca0000218

Cropley, D. H. (2010). Malevolent innovation: Opposing the dark side of creativity. In D. H. Cropley, A. J. Cropley, J. C. Kaufman, \& M. A. Runco (Eds.), The dark side of creativity (pp. 329-338). Cambridge University Press.

Cropley, D. H., Kaufman, J. C., \& Cropley, A. J. (2008). Malevolent creativity: A functional model of creativity in terrorism and crime. Creativity Research Journal, 20(2), 105-115. https://doi. org/10.1080/10400410802059424

De Dreu, C. K., Baas, M., \& Nijstad, B. A. (2008). Hedonic tone and activation level in the mood-creativity link: Toward a dual pathway to creativity model. Journal of Personality and Social Psychology, 94(5), 739-756. https://doi.org/10.1037/00223514.94.5.739

De Dreu, C. K. W., Baas, M., \& Nijstad, B. A. (2012). The emotive roots of creativity: Basic and applied issues on affect and motivation. In M. D. Mumford (Ed.), Handbook of organizational creativity (pp. 217-240). Elsevier.

De Dreu, C. K. Nijstad, B. A., \& Baas, M. (2011). Behavioral activation links to creativity because of increased cognitive flexibility. Social Psychological and Personality Science, 2(1), 72-80. https://doi.org/10.1177/1948550610381789

Emich, K. J., \& Vincent, L. C. (2020). Shifting focus: The influence of affective diversity on team creativity. Organizational Behavior and Human Decision Processes, 156, 24-37. https://doi.org/ 10.1016/j.obhdp.2019.10.002

Fanning, J. R., Keedy, S., Berman, M. E., Lee, R., \& Coccaro, E. F. (2017). Neural correlates of aggressive behavior in real time: A review of $\mathrm{fMRl}$ studies of laboratory reactive aggression. Current Behavioral Neuroscience Reports, 4(2), 138-150. https://doi.org/10.1007/s40473-017-0115-8

Fink, A., Bay, J. U., Koschutnig, K., Prettenthaler, K., Rominger, C., Benedek, M., Papousek, I., Weiss, E. M., Seidel, A., \& Memmert, D. (2019). Brain and soccer: Functional patterns of brain activity during the generation of creative moves in real soccer decision-making situations. Human Brain Mapping, 40(3), 755764. https://doi.org/10.1002/hbm.24408

Fink, A., \& Benedek, M. (2014). EEG alpha power and creative ideation. Neuroscience \& Biobehavioral Reviews, 44, 111-123. https://doi.org/10.1016/j.neubiorev.2012.12.002

Fink, A., Benedek, M., Koschutnig, K., Pirker, E., Berger, E., Meister, S., Neubauer, A. C., Papousek, I., \& Weiss, E. M. (2015). Training of verbal creativity modulates brain activity in regions associated with language- and memory-related demands. Human Brain Mapping, 36(10), 4104-4115. https://doi.org/ 10.1002/hbm.22901

Fink, A., Koschutnig, K., Benedek, M., Reishofer, G., Ischebeck, A., Weiss, E. M., \& Ebner, F. (2012). Stimulating creativity via the exposure to other people's ideas. Human Brain Mapping, 33(11), 2603-2610. https://doi.org/10.1002/hbm.21387

Fink, A., Perchtold, C., \& Rominger, C. (2018). Creativity and cognitive control in the cognitive and affective domains. In R. E. Jung \& $\mathrm{O}$. Vartanian (Eds.), The Cambridge handbook of the neuroscience of creativity (pp. 318-332). Cambridge University Press.

Fink, A., Reim, T., Benedek, M., \& Grabner, R. H. (2020). The effects of a verbal and a figural creativity training on different facets of creative potential. The Journal of Creative Behavior, 54(3), 676-685. https://doi.org/10.1002/jocb.402

Fink, A., Rominger, C., Benedek, M., Perchtold, C. M., Papousek, I., Weiss, E. M., Seidel, A., \& Memmert, D. (2018). EEG alpha activity during imagining creative moves in soccer decisionmaking situations. Neuropsychologia, 114, 118-124. https:// doi.org/10.1016/j.neuropsychologia.2018.04.025

Fink, A., Schwab, D., \& Papousek, I. (2011). Sensitivity of EEG upper alpha activity to cognitive and affective creativity interventions. International Journal of Psychophysiology, 82(3), 233239. https://doi.org/10.1016/j.ijpsycho.2011.09.003

Fink, A., Weiss, E. M., Schwarzl, U., Weber, H., de Assunção, V. L., Rominger, C., Schulter, G., Lackner, H. K., \& Papousek, I. (2017). Creative ways to well-being: Reappraisal inventiveness in the context of anger-evoking situations. Cognitive, Affective, \& Behavioral Neuroscience, 17, 94-105. https://doi.org/10.3758/ s13415-016-0465-9 
Fuchs, G. L., Kumar, V. K., \& Porter, J. (2007). Emotional creativity, alexithymia, and styles of creativity. Creativity Research Journal, 19(2-3), 233-245. https://doi.org/10.1080/10400410701397313

Gonen-Yaacovi, G., De Souza, L. C., Levy, R., Urbanski, M., Josse, G., \& Volle, E. (2013). Rostral and caudal prefrontal contribution to creativity: A meta-analysis of functional imaging data. Frontiers in Human Neuroscience, 7, Article 465. https://doi. org/10.3389/fnhum.2013.00465

Grabner, R. H., Krenn, J., Fink, A., Arendasy, M., \& Benedek, M. (2018). Effects of alpha and gamma transcranial alternating current stimulation (tACS) on verbal creativity and intelligence test performance. Neuropsychologia, 118, 91-98. https://doi. org/10.1016/j.neuropsychologia.2017.10.035

Gross, J. J., \& John, O. P. (2003). Individual differences in two emotion regulation processes: Implications for affect, relationships, and well-being. Journal of Personality and Social Psychology, 85(2), 348-362. https://doi.org/10.1037/00223514.85.2.348

Hao, N., Tang, M., Yang, J., Wang, Q., \& Runco, M. A. (2016). A New tool to measure malevolent creativity: The Malevolent Creativity Behavior Scale. Frontiers in Psychology, 7, Article 682. https:// doi.org/10.3389/fpsyg.2016.00682

Hao, N., Qiao, X., Cheng, R., Lu, K., Tang, M., \& Runco, M. A. (2020). Approach motivational orientation enhances malevolent creativity. Acta Psychologica, 203, Article 102985. https://doi.org/ 10.1016/j.actpsy.2019.102985

Harris, D. J., \& Reiter-Palmon, R. (2015). Fast and furious: The influence of implicit aggression, premeditation, and provoking situations on malevolent creativity. Psychology of Aesthetics, Creativity, and the Arts, 9(1), 54-64. https://doi.org/10.1037/ a0038499

Harris, D. J., Reiter-Palmon, R., \& Kaufman, J. C. (2013). The effect of emotional intelligence and task type on malevolent creativity. Psychology of Aesthetics, Creativity, and the Arts, 7(3), 237-244. https://doi.org/10.1037/a0032139

Hirt, E. R., Devers, E. E., \& McCrea, S. M. (2008). I want to be creative: Exploring the role of hedonic contingency theory in the positive mood-cognitive flexibility link. Journal of Personality and Social Psychology, 94(2), 214-230. https://doi.org/10.1037/ 0022-3514.94.2.94.2.214

Isen, A. M. (1984). Toward understanding the role of affect in cognition. In R. S. Wyer \& T. K. Srull (Eds.), Handbook of social cognition (Vol. 3, pp. 179-236). Erlbaum.

Isen, A. M., Daubman, K. A., \& Nowicki, G. P. (1987). Positive affect facilitates creative problem solving. Journal of Personality and Social Psychology, 52(6), 1122-1131. https://doi.org/10.1037/ 0022-3514.52.6.1122

Ivcevic, Z., Brackett, M. A., \& Mayer, J. D. (2007). Emotional intelligence and emotional creativity. Journal of Personality, 75(2), 199-236. https://doi.org/10.1111/j.1467-6494.2007. 00437.x

Jaarsveld, S., Fink, A., Rinner, M., Schwab, D., Benedek, M., \& Lachmann, T. (2015). Intelligence in creative processes: An EEG study. Intelligence, 49, 171-178. https://doi.org/10.1016/j. intell.2015.01.012

James, K., Clark, K., \& Cropanzano, R. (1999). Positive and negative creativity in groups, institutions, and organizations: A model and theoretical extension. Creativity Research Journal, 12(3), 211-226. https://doi.org/10.1207/s15326934crj1203_6

Jonason, P. K., Abboud, R., Tomé, J., Dummett, M., \& Hazer, A. (2017). The Dark Triad traits and individual differences in self-reported and other-rated creativity. Personality and Individual Differences, 117, 150-154. https://doi.org/10.1016/j.paid.2017.06.005

Joormann, J., \& Gotlib, I. H. (2010). Emotion regulation in depression: Relation to cognitive inhibition. Cognition and Emotion, 24(2), 281-298. https://doi.org/10.1080/02699930903407948
Karwowski, M., Lebuda, I., Szumski, G., \& Firkowska-Mankiewicz, A. (2017). From moment-to-moment to day-to-day: Experience sampling and diary investigations in adults' everyday creativity. Psychology of Aesthetics, Creativity, and the Arts, 11(3), 309324. https://doi.org/10.1037/aca0000127

Khorakian, A., Hemsworth, D., Jahangir, M., Maharati, Y., Bagherpour, E. S., \& Muterera, J. (2020). The effects of religious orientations on malevolent creativity: Role of positive emotions and spiritual intelligence. Creativity Research Journal. Advance Online Publication. https://doi.org/10.1080/10400419.2020.1818491

Kounios, J., \& Beeman, M. (2014). The cognitive neuroscience of insight. Annual Review of Psychology, 65, 71-93. https://doi. org/10.1146/annurev-psych-010213-115154

Kuška, M., Trnka, R., Mana, J., \& Nikolai, T. (2020). Emotional creativity: A meta-analysis and integrative review. Creativity Research Journal, 32(2), 151-160. https://doi.org/10.1080/10400419.2020.1751541

Lazarus, R. S., \& Folkman, S. (1984). Stress, appraisal, and coping. Springer.

Lubart, T. (2017). The 7 C's of creativity. The Journal of Creative Behavior, 51(4), 293-296. https://doi.org/10.1002/jocb.190

Luft, C. D. B., Zioga, I., Thompson, N. M., Banissy, M. J., \& Bhattacharya, J. (2018). Right temporal alpha oscillations as a neural mechanism for inhibiting obvious associations. Proceedings of the National Academy of Sciences, 115(52), E12144-E12152. https://doi.org/10.1073/pnas.1811465115

Madrid, H. P., \& Patterson, M. G. (2018). Affect and creativity. In R. Reiter-Palmon, V. Kennel, \& J. C. Kaufman (Eds.), Individual creativity in the workplace (pp. 245-265). Academic Press.

Malooly, A. M., Genet, J. J., \& Siemer, M. (2013). Individual differences in reappraisal effectiveness: The role of affective flexibility. Emotion, 13(2), 302-313. https://doi.org/10.1037/a0029980

Nijstad, B. A., De Dreu, C. K., Rietzschel, E. F., \& Baas, M. (2010). The dual pathway to creativity model: Creative ideation as a function of flexibility and persistence. European Review of Social Psychology, 21(1), 34-77. https://doi.org/10.1080/10463281003765323

Oppezzo, M., \& Schwartz, D. L. (2014). Give your ideas some legs: The positive effect of walking on creative thinking. Journal of Experimental Psychology: Learning, Memory, and Cognition, 40(4), 1142-1152. https://doi.org/10.1037/a0036577

Papousek, I., Ruch, W., Rominger, C., Kindermann, E., Scheidl, K., Schulter, G., Fink, A., \& Weiss, E. M. (2017). The use of bright and dark types of humour is rooted in the brain. Scientific Reports, 7, Article 42967. https://doi.org/10.1038/srep42967

Papousek, I., Weiss, E. M., Perchtold, C. M., Weber, H., Assuncao, V. L., Schulter, G., Lackner, H. K., \& Fink, A. (2017). The capacity for generating cognitive reappraisals is reflected in asymmetric activation of frontal brain regions. Brain Imaging and Behavior, 11(2), 577-590. https://doi.org/10.1007/s11682-016-9537-2

Perchtold, C. M., Fink, A., Rominger, C., Weber, H., de Assunção, V. L., Schulter, G., Weiss, E. M., \& Papousek, I. (2018). Reappraisal inventiveness: Impact of appropriate brain activation during efforts to generate alternative appraisals on the perception of chronic stress in women. Anxiety, Stress, \& Coping, 31(2), 206-221. https://doi.org/10.1080/10615806.2017.1419205

Perchtold, C. M., Papousek, I., Fink, A., Weber, H., Rominger, C., \& Weiss, E. M. (2019). Gender differences in generating cognitive reappraisals for threatening situations: Reappraisal capacity shields against depressive symptoms in men, but not women. Frontiers in Psychology, 10, Article 553. https://doi.org/ 10.3389/fpsyg.2019.00553

Perchtold, C. M., Papousek, I., Koschutnig, K., Rominger, C., Weber, H., Weiss, E. M., \& Fink, A. (2018). Affective creativity meets classic creativity in the scanner. Human Brain Mapping, 39(1), 393-406. https://doi.org/10.1002/hbm.23851

Perchtold, C. M., Weiss, E. M., Rominger, C., Fink, A., Weber, H., \& Papousek, I. (2019). Cognitive reappraisal capacity mediates the 
relationship between prefrontal recruitment during reappraisal of anger-eliciting events and paranoia-proneness. Brain and Cognition, 132, 108-117. https://doi.org/10.1016/j.bandc.2019.04.001

Perchtold-Stefan, C. M., Fink, A., Rominger, C., \& Papousek, I. (2020a). Motivational factors in the typical display of humor and creative potential: The case of malevolent creativity. Frontiers in Psychology, 11, Article 1213. https://doi.org/ 10.3389/fpsyg.2020.01213

Perchtold-Stefan, C. M., Fink, A., Rominger, C., \& Papousek, I. (2020b). Creative, angry, and antagonistic? Exploring the roots of malevolent creativity with a real-world idea generation task. The Journal of Creative Behavior. Advance online publication. https://doi.org/10.1002/jocb.484

Perchtold-Stefan, C. M., Fink, A., Rominger, C., \& Papousek, I. (2021). Failure to reappraise: Malevolent creativity is linked to revenge ideation and impaired reappraisal inventiveness in the face of stressful, anger-eliciting events. Anxiety, Stress, \& Coping. Advance online publication. https://doi.org/10.1080/ 10615806.2021.1918682

Perchtold-Stefan, C. M., Papousek, I., Rominger, C., Schertler, M., Weiss, E. M., \& Fink, A. (2020). Humor comprehension and creative cognition: Shared and distinct neurocognitive mechanisms as indicated by EEG alpha activity. Neurolmage, 213, Article 116695. https://doi.org/10.1016/j.neuroimage.2020.116695

Reiter-Palmon, R. (2018). Are the outcomes of creativity always positive? Creativity: Theories-Research-Applications, 5, 177181. https://doi.org/10.1515/ctra-2018-0016

Ritter, S. M., \& Mostert, N. (2017). Enhancement of creative thinking skills using a cognitive-based creativity training. Journal of Cognitive Enhancement, 1(3), 243-253. https://doi. org/10.1007/s41465-016-0002-3

Rominger, C., Fink, A., Benedek, M., Weber, B., Perchtold-Stefan, C. M., Papousek, I., \& Schwerdtfeger, A. R. (2021). Reliability and validity of a novel Ambulatory Battery of Creativity (ABC). Manuscript submitted for publication.

Rominger, C., Fink, A., Weber, B., Papousek, I., \& Schwerdtfeger, A. R. (2020). Everyday bodily movement is associated with creativity independently from active positive affect: A Bayesian mediation analysis approach. Scientific Reports, 10(1), 1-9. https://doi.org/10.1038/s41598-020-68632-9

Rominger, C., Koschutnig, K., Memmert, D., Papousek, I., Perchtold-Stefan, C. M., Benedek, M., Schwerdtfeger, A., \& Fink, A. (2021). Brain activation during the observation of real soccer game situations predicts creative goal scoring. Social Cognitive and Affective Neuroscience. Advance online publication. https://doi.org/10.1093/scan/nsab035

Rominger, C., Memmert, D., Papousek, I., Perchtold-Stefan, C., Weiss, E. M., Benedek, M., Schwerdtfeger, A., \& Fink, A. (2020). Female and male soccer players recruited different cognitive processes when generating creative soccer moves. Psychology of Sport \& Exercise, 50, Article 101748. https://doi.org/ 10.1016/j.psychsport.2020.101748

Rominger, C., Papousek, I., Perchtold, C. M., Benedek, M., Weiss, E. M., Schwerdtfeger, A., \& Fink, A. (2019). Creativity is associated with a characteristic U-shaped function of alpha power changes accompanied by an early increase in functional coupling. Cognitive, Affective, \& Behavioral Neuroscience, 19(4), 1012-1021. https://doi.org/10.3758/s13415-019-00699-y

Rominger, C., Papousek, I., Perchtold, C. M., Weber, B., Weiss, E. M., \& Fink, A. (2018). The creative brain in the figural domain: Distinct patterns of EEG alpha power during idea generation and idea elaboration. Neuropsychologia, 118, 13-19. https:// doi.org/10.1016/j.neuropsychologia.2018.02.013

Rosen, D., Oh, Y., Erickson, B., Zhang, F. Z., Kim, Y. E., \& Kounios, J. (2020). Dual-process contributions to creativity in jazz improvisations: An SPM-EEG study. Neurolmage, 213, Article 116632. https://doi.org/10.1016/j.neuroimage.2020.116632

Runco, M. A. (2004). Creativity. Annual Review of Psychology, 55, 657687. https://doi.org/10.1146/annurev.psych.55.090902.141502

Runco, M. A., \& Jaeger, G. J. (2012). The standard definition of creativity. Creativity Research Journal, 24(1), 92-96. https://doi. org/10.1080/10400419.2012.650092

Scott, G., Leritz, L. E., \& Mumford, M. D. (2004). The effectiveness of creativity training: A quantitative review. Creativity Research Journal, 16(4), 361-388. https://doi.org/10.1080/10400410409534549

Silvia, P. J., Beaty, R. E., Nusbaum, E. C., Eddington, K. M., LevinAspenson, H., \& Kwapil, T. R. (2014). Everyday creativity in daily life: An experience-sampling study of "little c" creativity. Psychology of Aesthetics, Creativity, and the Arts, 8(2), 183188. https://doi.org/10.1037/a0035722

Stein, M. I. (1953). Creativity and culture. The Journal of Psychology: Interdisciplinary and Applied, 36, 311-322. https://doi.org/ 10.1080/00223980.1953.9712897

Sternberg, R. J. (2010). The dark side of creativity and how to combat it. In D. H. Cropley, A. J. Cropley, J. C. Kaufman, \& M. A. Runco (Eds.), The dark side of creativity (pp. 316-328). Cambridge University Press.

Stevens, C. E., \& Zabelina, D. L. (2019). Creativity comes in waves: an EEG-focused exploration of the creative brain. Current Opinion in Behavioral Sciences, 27, 154-162. https://doi.org/ 10.1016/j.cobeha.2019.02.003

Tanggaard, L. (2013). The sociomateriality of creativity in everyday life. Culture \& Psychology, 19(1), 20-32. https://doi.org/ 10.1177/1354067X12464987

Webb, T. L., Miles, E., \& Sheeran, P. (2012). Dealing with feeling: A meta-analysis of the effectiveness of strategies derived from the process model of emotion regulation. Psychological Bulletin, 138(4), 775-808. https://doi.org/10.1037/a0027600

Weber, B., Koschutnig, K., Schwerdtfeger, A., Rominger, C., Papousek, I., Weiss, E. M., Tilp, M., \& Fink, A. (2019). Learning unicycling evokes manifold changes in gray and white matter networks related to motor and cognitive functions. Scientific Reports, 9(1), 1-11. https://doi.org/10.1038/s41598-019-40533-6

Weber, H., Loureiro de Assunção, V., Martin, C., Westmeyer, H., \& Geisler, F. C. (2014). Reappraisal inventiveness: The ability to create different reappraisals of critical situations. Cognition \& Emotion, 28(2), 345-360. https://doi.org/10.1080/02699931. 2013.832152

Zaehringer, J., Falquez, R., Schubert, A. L., Nees, F., \& Barnow, S. (2018). Neural correlates of reappraisal considering working memory capacity and cognitive flexibility. Brain Imaging and Behavior, 12(6), 1529-1543. https://doi.org/10.1007/s11682017-9788-6

\section{History}

Received December 22, 2020

Revision received March 5, 2021

Accepted April 7, 2021

Published online December 10, 2021

\section{Conflict of Interest}

We have no conflict of interest to disclose.

\section{Funding}

Part of the research reviewed in this paper was supported by the Austrian Science Fund (P27750 and P30362).

\section{ORCID}

Corinna M. Perchtold-Stefan

(iDhttps://orcid.org/0000-0002-8334-0574 


\section{Corinna M. Perchtold-Stefan}

Department of Psychology

University of Graz

Universitätsplatz 2

8010 Graz

Austria

corinna.perchtold@uni-graz.at

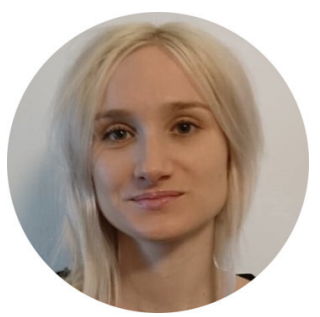

Corinna M. Perchtold-Stefan (PhD) is a senior scientist (Biological Psychology) at the Institute of Psychology, University of Graz. Her research targets the interface of cognition and emotion and focuses on emotion regulation and creativity in an affective context as exemplified by reappraisal inventiveness and malevolent creativity.

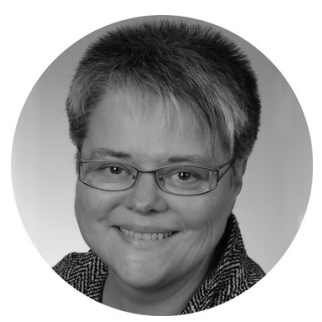

Ilona Papousek $(\mathrm{PhD})$ is a professor in Biological Psychology at the Institute of Psychology, University of Graz. Her research focuses on socio-emotional processes and emotion regulation, as well as humor and laughter, hemispheric asymmetries, and flexibility in emotional, cognitive, and physiological domains.

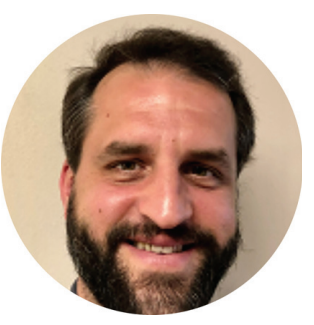

Christian Rominger (PhD) is a senior scientist (Biological and Health Psychology) at the Institute of Psychology, University of Graz. His research links creativity and health and focuses on the neuroscience of creativity also in more real-life domains like soccer, and the ecological momentary assessment of creative ideation.

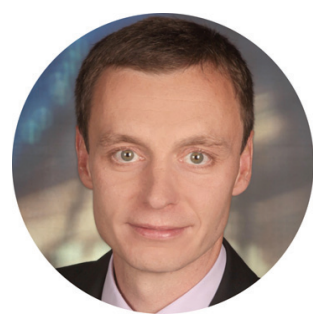

Andreas Fink (PhD) is a professor of Biological Psychology at the Institute of Psychology, University of Graz. His main research activities include the neuroscience of creativity and approaches to enhance creativity. His research also focuses on the effects of physical activity on cognitive, affective, and brain functions. 